This is the peer reviewed version of the following article: Lovatt, M. (2018), Becoming at home in residential care for older people: a material culture perspective. Sociology of Health \& IIIness, 40: 366-378, which has been published in final form at https://doi.org/10.1111/1467-9566.12568. This article may be used for non-commercial purposes in accordance With Wiley Terms and Conditions for self-archiving. 


\section{Becoming at home in residential care for older people: a material culture perspective}

\section{Introduction}

Residential homes for older people often encourage new residents to bring personal possessions with them, so that they can personalise their rooms and 'feel at home'. Previous research argues that belongings can help residents maintain a sense of identity on entering residential accommodation (Cram and Paton, 1993, Rowles, 1993). The implication is that through furnishing their rooms with objects from their former homes, residents can transfer a sense of personal identity, home and belonging to the new, unfamiliar, institutional room in the residential home. In this paper I challenge such assumptions, arguing that a sense of home cannot be transferred within, and reclaimed from, possessions, but emerges through ongoing interactions between residents and their material surroundings through social and relational practices.

Home, possessions and identity in later life

People's experiences, relationships and practices are mediated by their material surroundings. The ways in which personal possessions reflect and constitute people's identities, such that they are regarded as instrumental to, or embodiments of, a person's sense of self, have been studied in a range of contexts and at different stages of the life course (Belk, 1998, Cieraad, 2010, Hallam and Hockey, 2001, Parkin, 1999, Parrott, 2005). Much research into the relationship between people, belongings, and identity has focused on the home. While homes are not just physical phenomena, the meanings they have for their inhabitants are created in part through their material dimensions. Furniture and ornaments are chosen and displayed in order to portray people's ideas of who they are, and who they would like to be.

While homes and the objects they contain are intrinsically connected to people's identities throughout their lives, researchers have argued that the relationships between a person's home, possessions and identity assume greater significance in later life. Firstly, the relationship is regarded 
as more meaningful because of the sheer length of time older people have lived in their homes (assuming they have not frequently moved house). The greater the time spent in a home, the more time to develop associations between the people who live in the house, the objects within it, and the everyday, domestic practices which are carried out (Rowles, 1983, Shenk et al., 2004, Sixsmith, 1990). Secondly, homes are perceived as having enhanced meaning as 'bolsters of identity' for older people who become more physically and socially isolated in their homes, as a result of increased frailty or through the deaths of friends and relatives (Kearns and Andrews, 2005, Rubinstein, 1987). Homes and possessions are conceptualised as providing older people with an important sense of control and continuity at a time when they may be experiencing less control over their lives and environments (Paton and Cram, 1992, Stones and Gullifer, 2014, Whitmore, 2001).Thirdly, homes are appreciated by older people for being 'a warehouse of memories' (Stones and Gullifer, 2014: 16), and possessions become important mnemonics, providing continuity and serving as 'the individual's 'archive”' (McCracken, 1987: 209).

\section{Possessions in older people's residential homes}

Drawing on assumptions that relationships between people, homes and possessions are more significant in later life, previous studies have regarded the move from a person's own home into residential or nursing care as potentially traumatic, where a person is at risk of 'losing their identity' (Cram and Paton, 1993, Rowles, 1983, Ryvicker, 2009, Stones and Gullifer, 2014). Belongings have been conceptualised as having the potential to transfer a sense of place and identity, thus mitigating the potential risk to selfhood when moving to institutional accommodation (Rowles, 1993: 69).

Early research into residents' belongings in residential and nursing homes focused on the functional characteristics and meanings of 'cherished' possessions, and how they influenced residents' quality of life and control over their environment (Sherman and Newman, 1977-78, Wapner et al., 1990). Such studies concluded that belongings had 'adaptive properties' in helping residents adjust to life in residential homes, by acting as 'material records of past self-identity', thereby helping residents to 
maintain 'a stable and coherent self-image' (Cram and Paton, 1993: 23), and providing opportunities for residents to maintain control over certain aspects of their environment (Paton and Cram, 1992). More recently, Catharina Nord explored how residents' possessions 'anchored' residents to their everyday lives in the present, as well as representing their pasts. She also found that while some objects were primarily valued for how they symbolised residents' roles during their lives, other mundane objects such as televisions and chairs were also valued by residents for enabling them to spend time in their rooms as they chose (Nord, 2013).

I suggest that there are three key limitations that characterise this research. Firstly, by predominantly focusing on cherished possessions, previous studies have overlooked how more mundane objects can 'frame' our everyday practices and experiences in significant ways (Miller, 2010). Secondly, home and identity are conceptualised as phenomena which are fixed, and which can be stored and transferred in objects. This misunderstands the processual and fluid nature of home and identity, which are negotiated, and change in accordance with our changing social and material interactions (Degnen, 2007, Hockey and James, 2003, Jenkins, 2008, Laws, 1997, Smart, 2007). Thirdly, the relationship between humans and objects is conceptualised as one where objects are essentially passive, and have meaning ascribed to, and extracted from them. This fails to take into account the agency of material culture, and the active ways in which it contributes to shaping human action and meaning (Gabb, 2011, Miller, 2010).

\section{Material culture and theories of social practice and relationality}

Researchers of material culture have argued that meanings are not inherent within objects, but emerge from person-object interactions in the course of everyday social and relational practices (Kidron, 2012, Woodward, 2015, Fairhurst, 1997). I argue that practice and relational approaches are more useful in understanding how meaning emerges through ongoing social and material interactions between people and their belongings, than theories which assume objects to be primarily passive symbols. Practice-based approaches critique structural givens such as 'family' or 
'home', and draw attention to how such concepts are 'done' through everyday practices such as shopping, cooking and cleaning, which necessarily require interactions with materials (Finch and Mason, 2000, Morgan, 1996, Rinkinen et al., 2015). Relationality similarly deconstructs assumptions that arise from given relationships and looks instead at how relationships are constituted (Finch and Mason, 2000). Such approaches are also helpful in foregrounding the relationalities between people and objects. In emphasising the relational aspects of people's social interactions, attention is paid to how people's meaningful social and personal lives are influenced by their relational interactions with non-humans, including animals and objects (Gabb, 2011, Rinkinen et al., 2015, Tipper, 2011, Woodward, 2015). As with practice approaches, relationality recognises that the meanings which people derive from personal and social relationships are also mediated and conducted through materials. Instead of focusing on the different characteristics or properties of humans and objects, relational approaches focus on the qualities and nature of the relational interactions themselves.

In this paper, I use theories of practice and relationality (Carsten, 2004, Finch and Mason, 2000, Mason, 2004, Morgan, 1996) to argue that residents actively turned the spaces of their rooms into places of home. Rather than the meaning of home being inherent in objects, or felt subjectively by residents, meaning was generated through ongoing, everyday interactions between the two.

\section{Methodology}

The findings discussed in this paper form part of data collected through doctoral research. My aim was to understand how residents in older people's residential accommodation experienced home and everyday life through their interactions with material culture. While my original research question was primarily concerned with how possessions from residents' former homes helped residents 'become at home', during the course of my research I broadened my inquiry to include objects acquired since the move, as early fieldwork suggested these were also important in how residents' experienced home. I used an ethnographic approach, which allowed me to observe 
everyday life in the home, and to get to know the residents and staff members over time. The project received ethics approval from the Research Ethics Committee of the University of Sheffield.

While my doctoral research comprised fieldwork in two different residential homes, here I draw on findings from one home, The Cedars'. The Cedars is located on the border of semi-affluent and semideprived areas of a city in northern England. It is a two-storey, purpose-built home which accommodates over 40 residents and is run by a not-for-profit care provider. Each floor has two corridors, each of which contain a mix of residents' rooms, communal rooms and staff rooms. All of the bedrooms are en-suite and of a similar design. The home does not provide nursing care, and while it caters for older people who have dementia, I only included residents without dementia, who I judged to be in a position to give informed consent. In assessing whether or not a resident had the mental capacity to give informed consent, I used my own judgment and also took advice from residential home staff.

I collected data at The Cedars between July 2012 and June 2013 through participant observation, indepth interviews and taking photographs (in this paper I present findings from observational and interview data). I spent the first couple of months getting to know the residents and staff members, explaining my research to them, and identifying residents who were interested in participating in interviews. During the course of my fieldwork I usually visited the home twice a week in the daytime, and on each visit I chatted to residents and members of staff, observed daily life in the home, and sometimes took part in coordinated activity sessions. After each visit I recorded my reflections and observations in field notes. In order to explore the experiences of individual residents and learn about their belongings in more detail, I also conducted in-depth interviews. Eleven residents agreed to be interviewed - eight women and three men (see Table 1). Typical reasons why residents moved into The Cedars included ill health, loneliness and a desire to be closer to family members. 
Table 1: Characteristics of participants

\begin{tabular}{|l|l|l|}
\hline $\begin{array}{l}\text { Name } \\
\text { (pseudonym) }\end{array}$ & Age at interview & $\begin{array}{l}\text { Time spent in home at time } \\
\text { of interview }\end{array}$ \\
\hline Pam & 88 & 3 years \\
\hline Mary & 93 & 2 years, 6 months \\
\hline Dorothy & 88 & 18 years \\
\hline Susan & 74 & 2 years, 8 months \\
\hline Frances & 85 & 1 year, 6 months \\
\hline Polly & 90 & 4 months \\
\hline Stan & 74 & 4 months \\
\hline Michael & 84 & 4 years \\
\hline Annie & 89 & 5 months \\
\hline Irene & 92 & 2.5 months \\
\hline Peter & 98 & 6 weeks \\
\hline
\end{tabular}

All of the interviews took place in residents' rooms and most lasted between 40 minutes and one hour. Interview topics included the circumstances of the residents' move into the home, the objects in their rooms, and their attitudes towards feeling at home. I transcribed the interviews verbatim and analysed the transcripts and field notes together, coding them inductively using Nvivo 10 software. I then collapsed codes into overarching conceptual themes (Braun and Clarke, 2006). Combining field notes and interview transcripts allowed me to triangulate the data sources and verify my analysis, confirming, for instance, that my observations as recorded in my field notes substantiated claims made by residents in interviews about their everyday practices. My analysis was informed by Catherine Riessman's approach to thematic narrative analysis, which allows for the identification of overarching themes without the data being fragmented and losing its context within the narratives and biographies of the individual residents (Riessman, 2008). I felt that this was particularly important as many of the narratives which residents' told about their belongings 
referenced residents' experiences during the life course. While I identified themes which cut across all of the residents' experiences in The Cedars, I did not want to homogenise individual accounts. In this paper I focus on the theme 'becoming at home'.

\section{Findings and analysis}

I present two key findings which suggest that for residents, 'becoming at home', was an ongoing process, as evidenced through their social and material interactions. Firstly, the materiality of residents' rooms reflected multiple temporalities which were necessary to the residents feeling at home. The material culture in residents' rooms comprised possessions from their former homes (valued for their familiarity and evocation of important memories and significant relationships), but also objects acquired since the move, in response to day to day needs and future aspirations. Secondly, residents actively engaged with - and were shaped by - their material surroundings in everyday social and relational practices such as cleaning and hosting.

\section{The material temporalities of home}

Usually, objects taken into the residential home (either chosen directly by the resident themselves or, more often, by a family member on their behalf) included photographs, furniture, ornaments and televisions. Annie's room was typical in this respect, and Annie (89) described the things she brought with her and the reasons for doing so:

All my crystals there, they were the first things I [decided to take], and various little ornaments as you can see up there. And the clock. Small things, things that I did need, or didn't, well I needed the clock and things like that but, the crystals I did need, because I'd been collecting them, and they meant a lot to me. I had to part with a lot, because I just couldn't cope with them all, but they went to family, so that was ok.... brought my television with me, which was most important, in a sense. And my Skybox and things like that. Photographs, naturally.... I brought this chair [armchair which can recline], my electric bed, the little cabinet, the long cabinet there, and drawers, two sets of drawers. That was it. I needed those. So I brought just what was necessary, because I needed that [cabinet that TV is on] with it being sort of cupboard-cum-drawers. I needed it for my Skybox and DVD things and the top, I wanted it that wide because of the television. So that was really necessary, and of course drawers, everyone needs lots of drawer room. 
Annie emphasised the practical and 'necessary' items she brought with her such as her television and drawers, but also stated that she 'needed' her collection of crystals because of the meaning they had for her, highlighting the difficulty of distinguishing between items which might be thought of as 'functional' and those relating more to 'identity' (Miller, 2010).

Some objects reflected and embodied past experiences or relationships. Dorothy (88) had a pipe stand and pipes, which had belonged to her now deceased husband. Prominently displayed on her window sill, Dorothy told me:

[m]y husband smoked lots of pipes, and of course I bought those for him, and I wanted to have something to remember him by, so I brought them with me.

$\cdots$

Melanie: and, do you think about him when you look at them?

Dorothy: oh yes. I think about him all the time love. Yes, he was a very good husband, a marvellous husband. Yes, I was married 36 years.

The pipes, which had previously served a practical purpose for her husband, now had a predominantly symbolic meaning for Dorothy, showing that the meanings which objects have for people are not fixed, but can alter over time. Particular objects are not necessarily significant to us because of the type of object they are, but because of how we use them and how they come to be associated with particular relationships or memories. Consequently, it makes little sense to rigidly categorise people's possessions as 'cherished', 'sentimental', 'mundane', 'practical' etc. as previous studies have done (Cram and Paton, 1993, Csikszentmihalyi and Rochberg-Halton, 1981, Nord, 2013, Paton and Cram, 1992, Sherman, 1991, Sherman and Dacher, 2005, Sherman and Newman, 1977-78, Wapner et al., 1990), because objects may be all these things simultaneously, or have different primary meanings over time and in different places.

While belongings prompted reflections on the past, they were incorporated into residents' present lives through their positioning alongside other, more mundane and temporary items. Annie had been a nurse for fifteen years, and her pride in her career was embodied within a small figurine of an 
owl in a nurse's uniform that had been given to her by her granddaughter. While the owl nurse was a reminder of past achievements, its placement on Annie's fridge, next to more everyday items such as an empty water bottle and plastic containers also spoke to an 'ongoing-ness' within her room. This juxtaposition of objects that were treasured and displayed more for their symbolic meanings, with more mundane, transitory items, was typical of the residents' rooms. Two residents - Mary (93) and Peter (98) - always had piles of newspapers next to their armchairs, which they gradually worked their way through, and books, mugs and medicines were usually visible on coffee tables or sideboards. This partly reflected the limited space of the rooms and the habit of residents with restricted mobility to have everything they needed within reach (Nord, 2013). However I would also argue that it is similar to most homelike spaces, where shelves or mantelpieces may simultaneously contain relatively permanent display objects such as vases and framed photographs, as well as more temporary things such as postcards, shopping lists or keys (Hurdley, 2013). This material arrangement of the banal with the symbolic suggested movement and life, a sense that home life was going on 'as normal', despite 'home' being a room within a residential home.

As well as bringing items from their former homes, many residents also acquired new things - both on the point of moving in and also in an ongoing way. Several residents bought new furniture on moving into the home. Sometimes this was because their existing furniture wouldn't physically fit in the room, or because they had a younger relative who was moving into a new home and who could benefit from having the resident's cast off furniture, leaving the resident free to buy new items. Even after residents had settled in to their rooms, many of them continued to actively shape the materiality of their home by acquiring more objects. Sometimes this was to replace broken or outdated appliances such as clocks or televisions, while others bought things as and when they liked, or when the opportunity presented itself. Stan (74) had a mobility scooter and frequently bought items apparently at random from the local charity shop; these included a stool, a clock, and a wine rack ('nothing in it though, 'cause I don't drink! I just like the look of it'). Other residents who were less able to leave the residential home had other ways of adding to their rooms, for instance those 
with computers bought books and other items online. The Cedars also had an occasional jumble sale, which allowed residents to buy things for their rooms, and also Christmas presents for family members. Dorothy was an avid purchaser of jumble items, and many of her ornaments had been bought within the home. She also displayed pictures which she had made in the coordinated activity sessions, and along with other residents regularly received new photographs from family members to display. Other residents made more fundamental changes to their rooms. Susan (74) disliked the original magnolia-coloured walls in her room, and so arranged with the manager to hire a contractor to redecorate and have new curtains and a carpet. In this way, residents' sense of belonging in their rooms did not just derive from objects from their pasts and former homes, but from new acquisitions that reflected current activities and future aspirations.

\section{Practising being at home}

A sense of home was not instantly created by the residents' transference of objects from their previous homes into their rooms in The Cedars, and many residents spoke of how the initial weeks and months were difficult, and that it took time for them to settle in. However, over time, most residents I spoke to cultivated a sense of home in their individual rooms by establishing regular practices, routines and interactions with their material surroundings. Most residents chose to spend most of their time in their own rooms, but went to the communal dining rooms for meals and an opportunity to socialise with other residents. Some residents demonstrated control over, and responsibility for, their rooms through tasks such as cleaning, tidying and sorting their things, although the extent to which they did this depended partly on their physical abilities. It was notable that none of the three male interviewees showed any signs of actively maintaining the room through domestic tasks, and while most female residents owned fridges and sometimes kettles, the male residents did not appear to have a sense of being 'house proud' in a way that many of the female residents did. This is perhaps unsurprising, given that the residents were of a generation when it would have been commonplace for women to stay at home, look after children and make the home 
fit for 'public scrutiny' (Mason, 1989: 120), while men would have been largely responsible for paid work outside the home. Despite this evidence of gendered differences, all residents involved themselves in shaping their rooms into homes, whether it be through assuming domestic responsibilities, or investing time in their rooms through hobbies and activities.

None of the residents had to undertake any cleaning in their rooms, and many were physically unable to do so, or preferred to let the staff do this for them. However, some female residents chose to clean, tidy and rearrange their rooms. Susan had limited mobility as a result of having Parkinson's Disease, a bad foot and having had a stroke, but despite this she took an active role in maintaining her room, and when I visited her she was invariably cleaning. She cleaned her carpet everyday by manoeuvring around the room with a CarpetMate cleaner in one hand and her walking frame in the other; whenever I visited there was usually a blue cleaning cloth drying on the radiator. I asked her why cleaning her own room was so important to her:

Susan: I don't like untidiness and I don't like dirt. And that's the reason. I like to be clean, and I think, well anybody can come into my house and they'll find it clean and tidy. And I'm not afraid of anybody coming in - [the] queen can come in.

Melanie: and would it bother you if somebody else were to do the cleaning?

Susan: yes because they wouldn't do it like I do it!

Susan's use of the word 'house' to describe her room was striking, and I heard many other residents refer to their rooms as 'my flat' or 'my home'. For Susan, her room was a space that she had actively turned into a place through the time she spent there, the effort she put in to making it how she wanted, and maintaining it to her high standards.

Polly (90) had lived in The Cedars for four months when I first met her. Like Susan, Polly's room contained visual evidence of her pride in having a clean room, and she kept her Dust Buster close at hand on a table, next to more decorative objects. She had specifically asked her daughter to make sure that she would have a Dust Buster in her new 'flat', and was active in shaping her room to how she wanted it, moving her furniture if she felt that a new arrangement would work better. Like 
Susan, some residents told me that they conducted some housework because they believed that the staff did not do this as well as they could do so themselves. Pam (88) was limited in what she could do on account of chronic obstructive pulmonary disorder, but always made her own bed in the morning, because in her opinion the staff did not do this properly. Until she became too ill, Pam also used to do her own dusting, telling me that the cleaners 'dust round things, you know!' Despite being restricted in what she could do to maintain her room Pam was nevertheless house proud, and regarded having a clean, well-presented room as very important.

In addition to housework, many residents demonstrated their 'at home-ness' in their rooms through hosting visitors - a relational practice that was 'done' through material culture. Some residents had rooms that were clearly set up for visitors, and included comfortable settees and chairs. Such rooms gave the impression of being more living rooms than bedrooms, and in some cases furniture had been artfully arranged to subtly demarcate the bedroom area from the lounge space. Not all rooms contained furniture that enabled the resident to easily host visitors. This did not necessarily reflect the sociability of residents, but the limitations of the size of the room and the differing physical needs and priorities of residents. Annie, for example, often received visits from her son and other family members, but because of her limited mobility and her need for a wheelchair and furniture that allowed her to keep everything she might need during the day close at hand, she did not have any room for a sofa. She regretted this:

the resident who was here before, she left a chair like this with a settee to it. And that looks quite nice. And I wish I'd got a settee, because when people come to visit me they either have to fetch a chair or sit in there [wheelchair] or on the bed, you know. I could do with a little bit more space. But everything is, you know, where I can grab hold of, keeps me safe, sort of thing. I can switch from one thing to another quite easily.

Despite not having a spare chair, Annie was able to actively host visitors in other ways. Like many other female residents she had a fridge and kettle, and was able to offer visitors a cup of tea (even if they actually made it themselves). Other residents kept jars of biscuits or boxes of chocolates for 
when visitors arrived. Daniel Miller has written of 'the humility of things' (Miller, 1987: 85-108) to explain the way in which taken-for-granted objects shape our behaviour and influence our actions. I suggest that items such as chairs and kettles, while unspectacular, were instrumental in allowing residents to exert a sense of ownership in their home spaces, and framed and shaped the nature of residents' social interactions and relationships. Care staff went round all the residents' rooms in the morning and afternoon with a tea trolley. This often coincided with one of my visits, and on many occasions after being asked by care staff if they would like a cup of tea, residents would then turn to me and ask if I would also like a drink, giving me the impression that residents felt in control of their rooms. One resident, Polly, also performed this assuredness in, and ownership of, her material surroundings outside her room. On several occasions as I left her room she would stand up, kiss me on the cheek and accompany me to the stairwell along the corridor, 'in case you don't know where you're going', demonstrating both concern for her visitor as well as her own knowledge of her material home.

Although generally able to exercise agency in their rooms, there were 'institutional elements' to The Cedars which restricted residents' ability to be 'at home'. For instance, staff and residents sometimes clashed over the temperature of rooms, and whether or not windows could be opened. Additionally, a couple of residents complained of the lack of storage space. Most people's homes contain space in which to store items, and while not visible, these objects are still part of the home, and periodically sorting through things is part of the practice of 'moving things along' (Gregson et al., 2007) which is itself part of being at home. The lack of adequate storage space therefore prevented some residents from 'practising home' in this way.

\section{Discussion}

In this article I suggest that residents of The Cedars 'became at home' in their rooms through their interactions with material culture. Residents furnished their rooms with belongings brought from their former homes, and also objects which they continued to acquire, whether out of a need to 
replace broken items, a desire to try out a new aesthetic, or simply because they made an impulse purchase when something caught their eye. Permanent possessions such as ornaments, televisions and tables, shared space with more transitory materials like newspapers and medicine.

Consequently, the materiality of residents' rooms comprised multiple temporalities of past, present and future, and invoked a sense of 'everydayness'. The everyday nature of home was also demonstrated through residents' routine practices such as cleaning and hosting, which were mediated through their material surroundings. In 'doing' and 'performing' home in this way, residents demonstrated their control of, and belonging in, the materiality of their rooms.

By calling attention to everyday material culture, this research supports previous studies which argue that often unnoticed objects such as handbags, books or armchairs can illuminate residents' experiences in older people's homes (Buse and Twigg, 2014, Nord, 2013). While the significance of 'the everyday' is recognised within sociology (Neal and Murji, 2015), the importance of the 'fine grain of day-to-day existence' (Peace et al., 2006: 24) has been largely overlooked in studies of material culture in older people's residential accommodation, which have privileged studying 'cherished' or 'treasured' belongings. This has reinforced a sense that moving into long-term care is inevitably experienced as a rupture, 'a transition from "doing for" to "being done for", as well as a transition from independence to dependence' (Higgins, 1989: 141). The findings I present in this article suggest that life goes on, and that residents continue to 'do home', albeit within a different setting and with more limited capabilities.

I suggest that residents actively turned the spaces of their rooms into places of home through habitual practices and by adding to their material surroundings. This supports findings that routines such as housework and hosting are crucial in enabling older people to develop a sense of home (Percival, 2002), and that conversely, residents who have everything done for them by staff, feel helpless and a lack of control (Willcocks et al., 1987). It also draws on the theory that 'becoming at home', 'is essentially an active process which involves forms of work, "housework" in the broadest 
sense of that term' (Allan and Crow, 1989: 11), and that home cannot simply be transferred within objects. Objects are not just passive repositories or symbols of meaning; they do not merely reflect a sense of home, but actively constitute home (Miller, 2010). I suggest that the possessions were not in themselves sufficient to instil a sense of being at home; that came from the work that residents did in incorporating the objects into a new sense of home through routines and new purchases to fit into their rooms. Theories of practice and relationality are useful here in understanding home as a process, where residents 'did' home and relationships through interacting with the things around them (Morgan, 1996, Woodward, 2015).

The processual nature of home also emphasises the significance of imagination in place-making. While the importance of imagining and materialising future plans when making a home has been acknowledged in earlier stages of the life course (Cieraad, 2010, Holdsworth and Morgan, 2005), it has been neglected in studies of home in older age, which have instead focused on the significance of the past, and continuities with former homes in enabling older people to have a sense of belonging in a new residential setting. However, Malcolm Cutchin has argued that in addition to transferring possessions and engaging in routines and place-making activities, residents moving to assisted living facilities must also be able to use their imaginations in order to think about what would enable them to feel more at home: '[w]hile much scholarly attention has been focused on the role of memories of older people in establishing a relationship with a new place, it is important to realize that the ability to see possible futures is equally, if not more, important' (Cutchin, 2013: 120). Failure to consider future temporal dimensions in place-making in older age reinforces an idea that older people are primarily past-oriented, and have no meaningful future.

My findings have practical implications for residential and nursing homes. To date, care homes' acknowledgement of the importance of material culture has centred on the potential for objects $t$ in reminiscence therapy (Sherman, 1991, Sherman and Dacher, 2005, Phenice and Griffore, 2013), and a general encouragement of residents to bring existing possessions into the home in order to 
facilitate a sense of belonging and familiarity. The built design of care homes can have a significant impact on residents' quality of life (Barnes, 2003), and homes should be designed to enable residents to navigate the buildings as easily as possible, provide them with adequate storage space, and allow them the space to engage in everyday practices within their rooms. Staff should also consider allowing residents the freedom to open windows and control their own heating. As previous research has noted, being overly risk-averse can undermine residents' ability to experience control and independence (Taylor, 2006). The importance to some residents of being able to host visitors, emphasises how homes continue to be social spaces even in later life. This supports research which found that architects of supported housing do not always take into account residents' relational lives when designing homes, making it difficult for residents to continue certain social and relational practices (Fairhurst, 2007, Fairhurst, 2000). Care homes could also frame the move to residential care as an opportunity to buy new furniture and other personal effects. Such initiatives might not be welcomed by all residents, but could help to provide a positive message that tempers the dominant narrative that a move to residential care represents an ending and a loss of possessions acquired over a lifetime.

This is a study of just one residential home, and focuses on the experiences of eleven residents who did not have dementia and were relatively physically able. Although other research suggests that physical disabilities do not necessarily prevent residents from living active lives through engaging with their material surroundings (Nord, 2013), further research is needed to explore how physical frailty and cognitive impairments may affect residents' ability to shape their routines and home spaces. My research cannot claim to show what is typical of residential homes for older people, but I suggest that its importance lies in showing what is possible. In revealing residents' everyday social and relational practices as mediated by material culture, it suggests that being at home in an older people's residential home is not only feasible, but is perhaps not so different from what it is to be at home at other stages of the life course and in other settings. This challenges conceptualisations of 
older people's homes - and older age itself - as somehow unknowable, unfamiliar and imagined (Gilleard and Higgs, 2011, Hazan, 1980, Hazan, 2002, Higgs and Gilleard, 2015).

\section{Acknowledgments}

My thanks to the study participants, the guest editors of this special issue, and three anonymous reviewers.

\section{References}

ALLAN, G. \& CROW, G. 1989. Introduction. In: ALLAN, G. \& CROW, G. (eds.) Home and family: Creating the domestic sphere. Basingstoke: MacMillan.

BARNES, S. 2003. Space, Choice and Control, and Quality of Life in Care Settings for Older People. $\mathrm{PhD}$, University of Sheffield.

BELK, R. 1998. Possessions and the Extended Self. Journal of Consumer Research, 15, 139-168.

BRAUN, V. \& CLARKE, V. 2006. Using thematic analysis in psychology. Qualitative Research in Psychology,, 3, 77-101.

BUSE, C. \& TWIGG, J. 2014. Women with dementia and their handbags: negotiating identity, privacy and 'home' though material culture. Journal of Aging Studies, 30, 14-22.

CARSTEN, J. 2004. After Kinship, Cambridge, Cambridge University Press.

CIERAAD, I. 2010. Homes from home: memories and projections. Home Cultures, 7, 85-102.

CRAM, F. \& PATON, H. 1993. Personal possessions and self-identity: the experiences of elderly women in three residential settings. Australasian Journal on Ageing, 12, 19-24.

CSIKSZENTMIHALYI, M. \& ROCHBERG-HALTON, E. 1981. The Meaning of Things: Domestic Symbols and the Self, Cambridge, Cambridge University Press.

CUTCHIN, M. P. 2013. The complex process of becoming at-home in assisted living. In: ROWLES, G. D. \& BERNARD, M. (eds.) Environmental Gerontology: Making meaningful places in old age. New York: Springer Publishing Company.

DEGNEN, C. 2007. Back to the future: temporality, narrative and the ageing self. In: HALLAM, E. \& INGOLD, T. (eds.) Creativity and Cultural Improvisation. Oxford: Berg.

FAIRHURST, E. 1997. Recalling life: analytical issues in the use of 'memories' In: JAMIESON, A., HARPER, S. \& VICTOR, C. (eds.) Critical Approaches to Ageing and Later Life. Buckingham: Open University Press.

FAIRHURST, E. 2000. Utilising space in sheltered housing or 'fitting a quart into a pint pot': perspectives of architects and older people. Environment and Planning D: Society and Space, 18, 761-776.

FAIRHURST, E. 2007. Theorising sleep practices and later life: moving to sheltered housing. Sociological Research Online, 12.

FINCH, J. \& MASON, J. 2000. Passing on: kinship and inheritance in England, London, Routledge.

GABB, J. 2011. Family Lives and Relational Living: Taking Account of Otherness. Sociological Research Online, 16. 
GILLEARD, C. \& HIGGS, P. 2011. Ageing abjection and embdiment in the fourth age. Journal of Aging Studies, 25, 135-142.

GREGSON, N., METCALFE, A. \& CREWE, L. 2007. Moving things along: the conduits and practices of divestment in consumption. Transactions of the Institute of British Geographers, 32, 187200.

HALLAM, E. \& HOCKEY, J. 2001. Death, Memory and Material Culture, Oxford, Berg.

HAZAN, H. 1980. The limbo people: a study of the constitution of time universe among the aged, London, Routledge \& Kegan Paul.

HAZAN, H. 2002. The home over the hill: towards a modern cosmology of institutionalization. Journal of Aging Studies, 16, 323-344.

HIGGINS, J. 1989. Homes and Institutions. In: ALLAN, G. \& CROW, G. (eds.) Home and family: Creating the domestic sphere. Basingstoke: MacMillan.

HIGGS, P. \& GILLEARD, C. 2015. Rethinking old age: theorising the fourth age, London, Palgrave.

HOCKEY, J. \& JAMES, A. 2003. Social Identities Across the Life Course, Basingstoke, Palgrave MacMillan.

HOLDSWORTH, C. \& MORGAN, D. 2005. Transitions in context: leaving home, independence and adulthood, Maidenhead, Open University Press.

HURDLEY, R. 2013. Home, materiality, memory and belonging: keeping culture, Basingstoke, Palgrave Macmillan.

JENKINS, R. 2008. Social Identity, Abingdon, Routledge.

KEARNS, R. A. \& ANDREWS, G. J. 2005. Placing ageing: positionings in the study of older people. In: ANDREWS, G. J. \& PHILLIPS, D. R. (eds.) Ageing and place: perspectives, policy, practice. Oxford: Routledge.

KIDRON, C. A. 2012. Breaching the wall of traumatic silence: Holocaust survivor and descendant person - object relations and the material transmission of the genocidal past. Journal of Material Culture, 17, 3-21.

LAWS, G. 1997. Spatiality and age relations. In: JAMIESON, A., HARPER, S. \& VICTOR, C. (eds.) Critical approaches to ageing and later life. Buckingham: Open University Press.

MASON, J. 1989. Reconstructing the public and the private: the home and marriage in later life. In: ALLAN, G. \& CROW, G. (eds.) Home and family: Creating the domestic sphere. Basingstoke: Macmillan

MASON, J. 2004. Personal narratives, relational selves: residential histories in the living and telling. Sociological Review, 52, 162-179.

MCCRACKEN, G. 1987. Culture and consumption among the elderly: three research objectives in an emerging field. Ageing \& Society, 7, 203-224.

MILLER, D. 1987. Material Culture and Mass Consumption, Oxford, Basil Blackwell Ltd.

MILLER, D. 2010. Stuff, Cambridge, Polity Press.

MORGAN, D. 1996. Family connections, Cambridge, Polity.

NEAL, S. \& MURJI, K. 2015. Sociologies of Everyday Life: Editors' Introduction to the Special Issue. Sociology, 49, 811-819.

NORD, C. 2013. A day to be lived. Elderly people's possessions for everyday life in assisted living. Journal of Aging Studies, 27, 135-142.

PARKIN, D. 1999. Mementoes as transitional objects in human displacement. Journal of Material Culture, 4, 303-320.

PARROTT, F. R. 2005. "It's not forever": The Material Culture of Hope. Journal of Material Culture, 10, 245-262.

PATON, H. \& CRAM, F. 1992. Personal possessions and environmental control: the experiences of elderly women in three residential settings. Journal of Women \& Aging, 4, 61-78.

PEACE, S., HOLLAND, C. \& KELLAHER, L. 2006. Environment and Identity in Later Life, Maidenhead, Open University Press. 
PERCIVAL, J. 2002. Domestic spaces: uses and meanings in the daily lives of older people. Ageing \& Society, 22, 729-749.

PHENICE, L. A. \& GRIFFORE, R. J. 2013. The Importance of Object Memories for Older Adults. Educational Gerontology, 39, 741-749.

RIESSMAN, C. K. 2008. Narrative Methods for the Human Sciences, London, Sage Publications Ltd.

RINKINEN, J., JALAS, M. \& SHOVE, E. 2015. Object relations in accounts of everyday life. Sociology, 49, 870-885.

ROWLES, G. D. 1983. Place and personal identity in old age: observations from Appalachia. Journal of Environmental Psychology, 3, 299-313.

ROWLES, G. D. 1993. Evolving images of place in aging and 'aging in place'. Generations, 17, 65-70.

RUBINSTEIN, R. L. 1987. The Significance of Personal Objects to Older People. Journal of Aging Studies, 1, 225-238.

RYVICKER, M. 2009. Preservation of self in the nursing home: contradictory practices within two models of care. Journal of Aging Studies, 23, 12-23.

SHENK, D., KUWAHARA, K. \& ZABLOTSKY, D. 2004. Older women's attachments to their home and possessions. Journal of Aging Studies, 18, 157-169.

SHERMAN, E. 1991. Reminiscentia: cherished objects as memorabilia in late-life resminiscence. International Journal of Aging and Human Development, 33, 89-100.

SHERMAN, E. \& DACHER, J. 2005. Cherished Objects and the Home: Their Meaning and Roles in Later Life. In: ROWLES, G. D. \& CHAUDHURY, H. (eds.) Home and Identity in Late Life. New York: Springer Publishing Company.

SHERMAN, E. \& NEWMAN, E. S. 1977-78. The Meaning of Cherished Personal Possessions for the Elderly. International Journal of Aging and Human Development, 8, 181-192.

SIXSMITH, A. J. 1990. The meaning and experience of 'home' in later life. In: BYTHEWAY, B. \& JOHNSON, J. (eds.) Welfare and the ageing experience. Aldershot: Avebury.

SMART, C. 2007. Personal Life, Cambridge, Polity Press.

STONES, D. \& GULLIFER, J. 2014. 'At home it's just so much easier to be yourself': older adults' perceptions of ageing in place. Ageing \& Society.

TAYLOR, B. J. 2006. Risk Management Paradigms in Health and Social Services for Professional Decision Making on the Long-Term Care of Older People. British Journal of Social Work, 36, 1411-1429.

TIPPER, B. 2011. Pets and Personal Life. In: MAY, V. (ed.) Sociology of Personal Life. Basingstoke: Palgrave.

WAPNER, S., DEMICK, J. \& REDONDO, J. P. 1990. Cherished possessions and adaptation of older people to nursing homes. The International Journal of Aging and Human Development, 31, 219-235.

WHITMORE, H. 2001. Value that Marketing Cannot Manufacture: Cherished Possessions as Links to Identity and Wisdom. Generations, 25, 57-63.

WILLCOCKS, D., PEACE, S. \& KELLAHER, L. 1987. Private Lives in Public Places: a research-based critique of residential life in local authority old people's homes, London, Tavistock Publications.

WOODWARD, S. 2015. The Hidden Lives of Domestic Things: accumulations in Cupboards, Lofts and Shelves. In: CASEY, E. \& TAYLOR, Y. (eds.) Intimacies, Critical Consumption and Diverse Economies. Basingstoke: Palgrave Macmillan.

\footnotetext{
i Pseudonyms are used to disguise the identity of the residential home and the residents
} 